\title{
Intratracheal Transplantation of Amnion-Derived Mesenchymal Stem Cells Ameliorates Hyperoxia-Induced Neonatal Hyperoxic Lung Injury via Aminoacyl-Peptide Hydrolase
}

\author{
Zhenghao $\mathrm{Li}^{1,2}$, Xiangcui Gong ${ }^{3}$, Dong $\mathrm{Li}^{4}$, Xiaofei Yang ${ }^{2}$, Qing $\mathrm{Shi}^{4}$, Xiuli $\mathrm{Ju}^{1,4}$ \\ ${ }^{1}$ Department of Pediatrics, Qilu Hospital of Shandong University, Fi'nan, China \\ ${ }^{2}$ Department of Pediatrics, Yidu Central Hospital of Weifang, Qingzhou, China \\ ${ }^{3}$ Department of Pediatrics, Qingdao Women and Children's Hospital, Qingdao, China \\ ${ }^{4}$ Stem Cell and Regenerative Medicine Research Center of Shandong University, Finan, China
}

Background and Objectives: Bronchopulmonary dysplasia (BPD) has major effects in premature infants. Although previous literature has indicated that mesenchymal stem cells (MSCs) can alleviate lung pathology in BPD newborns and improve the survival rate, few research have been done investigating significantly differentially expressed genes in the lungs before and after MSCs therapy. The aim of this study is to identify differentially expressed genes in lung tissues before and after hAD-MSC treatment.

Methods and Results: Human amnion-derived MSCs (hAD-MSCs) were cultured and met the MSCs criteria for cell phenotype and multidirectional differentiation. Then we confirmed the size of hAD-MSCs-EXOs and their expressed markers. An intratracheal drip of living cells showed the strongest effect on NHLI compared to cellular secretions or exosomes, both in terms of ameliorating pulmonary edema and reducing inflammatory cell infiltration. Through gene chip hybridization, PCR, and western blotting, acylaminoacyl-peptide hydrolase (APEH) expression was found to be significantly decreased under hyperoxia, and significantly increased after hAD-MSC treatment.

Conclusions: The intratracheal transplantation of hAD-MSCs ameliorated NHLI in neonatal rats through APEH.

Keywords: Bronchopulmonary dysplasia, Cell therapy, Human amniotic mesenchymal stem cells, Acylaminoacyl-peptide hydrolase

Received: September 18, 2019, Revised: March 2, 2020,

Accepted: March 30, 2020, Published online: April 30, 2020

Correspondence to Xiuli Ju

Department of Pediatrics, Qilu Hospital of Shandong University,

No. 107 Wenhuaxilu Road, Ji'nan, Shandong Province 250012, China

Tel: +86-0531-82169215, Fax: +86-0531-86927544

E-mail: jxlqlyy@163.com

(a) This is an open-access article distributed under the terms of the Creative Commons Attribution Non-Commercial License (http://creativecommons.org/ licenses/by-nc/4.0/), which permits unrestricted non-commercial use, distribution, and reproduction in any medium, provided the original work is properly cited.

Copyright (C) 2020 by the Korean Society for Stem Cell Research

\section{Introduction}

Due to the widespread use of mechanical ventilation and hyperoxia, the fetal survival rate has greatly improved; however, the incidence of bronchopulmonary dysplasia (BPD) has also increased. BPD majorly affects the growth, development, and quality of life of premature infants. Although hormone treatments can reduce inflammation, the use of hormones also increases the risk of hypertension, hyperglycemia, gastrointestinal bleeding, intestinal perforation, and hypertrophic obstructive cardiomyopathy in newborns (1). Hormones also show direct toxicity towards the developing brain of newborns, which can lead to neuron necrosis. Hormones can also interfere with and inhibit brain development (2). Exogenous pulmo- 
nary surfactant (PS) can promote alveolar development, improve lung function, and reduce the severity of BPD. However, PS is only effective over a short-term period, and is not effective for the long-term improvement of lung function (3). In addition, treatment with vitamin A (4), superoxide dismutase (SOD), erythropoietin, nitric oxide inhalation, and caffeine (5) have also showed protective anti-inflammatory effects on brain development; however, there is no conclusive evidence confirming that these methods have long-term beneficial effects on lung development. Therefore, new effective therapies for BPD are urgently required.

In earlier papers reported by our laboratory, we found that umbilical cord mesenchymal stem cells (UC-MSCs) can improve the survival rate of rats with acute lung injury induced by lipopolysaccharide (LPS), and reduced inflammatory cell infiltration and inflammatory factors in the lungs (6). Thus, UC-MSCs may show a therapeutic basis in promoting anti-inflammatory homeostasis and reducing oxidative stress. Recently, many animal models and clinical trials have also shown that MSCs can reduce pulmonary fibrosis, improve lung structure, and improve the survival rate in BPD patients. MSCs play an important role in coordinating the growth of epithelial cells and endothelial cells in lung development $(7,8)$. Moreover, recent phase I clinical trials and 2-year follow-up have shown that allogeneic bone marrow mesenchymal stem cell transplantation for BPD in premature infants is feasible, and its short-term and long-term safety has also been demonstrated $(8,9)$. However, the mechanism of MSCs in the treatment of BPD is still unclear, and its efficiency needs to be further improved. It is thus important to identify stem cells that are more effective for BPD treatment and to explore the molecular basis of their mechanism of action.

Human amnion-derived mesenchymal stem cells (hADMSCs) not only have the characteristics of MSCs, but also express several characteristics similar to embryonic stem cells (10). In addition, the method for obtaining hADMSCs is safe, non-invasive and ethical for both mothers and infants (11). In this study, we evaluated whether the intratracheal transplantation of hAD-MSC-derived exosomes (EXOs) would be as effective as treatment with $\mathrm{hAD}-\mathrm{MSCs}$ alone in a neonatal hyperoxic lung injury (NHLI) rat model. We further identified differentially expressed genes in lung tissues before and after hAD-MSC treatment.

\section{Materials and Methods}

\section{Preparation of hAD-MSCs}

Human placentas $(\mathrm{n}=10$; normal clinically term pregnancies) were collected from healthy donors who received cesarean sections at the Qilu Hospital of Shandong University, China. The use of placentas was approved by the Ethics Committee of Qilu Hospital of Shandong University, and written informed consent was obtained from all donors.

Under sterile conditions, the amniotic membrane was stripped from the placenta and cut into fragments with sharp scissors. At $37^{\circ} \mathrm{C}$, the debris is digested with $0.05 \%$ trypsin (Sigma Aldrich, St. Louis, MO, USA) for $2 \mathrm{~h}$ with shaking. The tissue debris obtained after digestion was then centrifuged at $120 \times \mathrm{g}$ for $10 \mathrm{~min}$. The supernatant was discarded and amniotic debris was re-digested in 2 $\mathrm{mg} / \mathrm{mL}$ type II collagenase (Sigma Aldrich) containing 0.1 $\mathrm{mg} / \mathrm{mL}$ DNase I (Sigma Aldrich) and 10\% fetal bovine serum (FBS; Gibco; Thermo Fisher Scientific, Waltham, MA, USA) for $1 \mathrm{~h}$ at $37^{\circ} \mathrm{C}$ with shaking. The undigested tissue was removed by filtering. The filtrate was washed with Hanks' Balanced Salt Solution (HBSS) and resuspended in complete media composed of Dulbecco's modified Eagle's medium (DMEM)/F-12 supplemented with 10\% FBS, $100 \mathrm{U} / \mathrm{mL}$ penicillin, and $100 \mathrm{~g} / \mathrm{mL}$ streptomycin (Gibco) in $100 \%$ humidity with $5 \% \mathrm{CO}_{2}$ and $21 \% \mathrm{O}_{2}$ at $37^{\circ} \mathrm{C}$. hAD-MSCs at the passage 3 were used for subsequent tests.

\section{Cell phenotyping of hAD-MSCs}

Flow cytometry was performed to characterize hADMSCs. The following phycolerythrin (PE)-labeled antibodies were used to analyze cell phenotypes: anti-human CD29 (557332), CD31 (560983), CD34 (550761), CD44 (562818), CD45 (560975), CD73 (562430), CD90 (561970), and CD105 (560839) (all diluted $1: 10$; BD Co., San Diego, CA, USA). Next, $1 \times 10^{6}$ cells were stained with $10 \mu \mathrm{L}$ each antibody in $100 \mu \mathrm{L}$ phosphate-buffered saline (PBS) for $15 \mathrm{~min}$ at room temperature. Flow cytometry was performed using the Guava easyCyte 6HT (EMD Millipore, Billerica, MA, USA), and the data were examined with Guava Incyte software (version 2.8, EMD Millipore).

\section{Differentiation capacity}

To investigate the differentiation ability of these adherent cells, passage 4 cells were cultured under corresponding conditions according to previous published literature (12). Cells were cultured at a density of $2 \times 10^{4}$ cells $/ \mathrm{cm}^{2}$ and replaced with induction medium. Osteogenic differ- 
entiation medium consisted of L-DMEM supplemented with $10 \% \mathrm{FBS}, 0.1 \mu \mathrm{M}$ dexamethasone, $50 \mathrm{mM} \beta$-glycerol phosphate, and $0.2 \mathrm{mM}$ ascorbic acid (Sigma Aldrich). The basic medium for adipose-induced differentiation is high-glucose DMEM. Additional compounds include 0.25 $\mathrm{mM}$ 3-isobutyl-1-methylxanthine, $0.1 \mu \mathrm{M}$ dexamethasone, $0.1 \mathrm{mM}$ indomethacin (Sigma Aldrich), $6.25 \mu \mathrm{g} / \mathrm{mL}$ insulin (PeproTech, Rocky Hill, NJ, USA), and 10\% FBS (Gibco). Cells grown in normal growth medium served as the control. To induce chondrogenic differentiation, cells were transferred into $15-\mathrm{mL}$ polypropylene tubes and centrifuged at $240 \times \mathrm{g}$ for $5 \mathrm{~min}$; the pellet was collected and treated with chondrogenic medium for 3 weeks. Chondrogenic medium consists of high-glucose DMEM (Bio-Fluid Technologies, Rockville, MD, USA) supplemented with 0.1 $\mu \mathrm{M}$ dexamethasone, $50 \mu \mathrm{g} / \mathrm{mL}$ ascorbic acid, $100 \mu \mathrm{g} /$ $\mathrm{mL}$ sodium pyruvate, $40 \mu \mathrm{g} / \mathrm{mL}$ proline (Sigma Aldrich), $10 \mathrm{ng} / \mathrm{mL}$ transforming growth factor (TGF)- $\beta 1$, and 50 $\mathrm{mg} / \mathrm{mL}$ ITS + premix $(6.25 \mu \mathrm{g} / \mathrm{mL}$ insulin, $6.25 \mu \mathrm{g} / \mathrm{mL}$ transferrin, $6.25 \mathrm{ng} / \mathrm{mL}$ selenius acid, $1.25 \mathrm{mg} / \mathrm{mL}$ bovine serum albumin (BSA), and $5.35 \mathrm{mg} / \mathrm{mL}$ linoleic acid; BD Co.). The differentiation media were changed every 3-4 $\mathrm{d}$.

To detect adipose orientation induced differentiation, cells were fixed and stained with oil-red O (Sigma Aldrich) for 10 minutes. Chondrogenic differentiation was evaluated with anti-Collagen II antibody (ab34712, dilution $1: 250$, Abcam, Cambridge, UK) for $45 \mathrm{~min}$ at $37^{\circ} \mathrm{C}$, and then peroxidase-conjugated secondary antibodies (CWBIO, dilution $1: 200$ ) were added for $30 \mathrm{~min}$ at room temperature. The cells were then incubation with DAB chromogen (CWBIO) and counterstained with haematoxylin. For evaluation of mineralized matrix, cells were stained with Alizarin-red S (Sigma Aldrich). In addition, osteogenic differentiation was also stained with chromogenic alkaline phosphatase activity (ALP) assay kit (Jiancheng Corp, Nanjing, China).

\section{Preparation of conditioned medium}

For conditioned medium (CM) collection, fresh full medium was replaced when hAD-MSCs reached $70 \sim 80 \%$ confluency. After $24 \mathrm{~h}$, the medium was collected and centrifuged at $1000 \times \mathrm{g}$ for $20 \mathrm{~min}$ with a $0.1-\mu \mathrm{m}$ pore filter to remove detached MSCs and cellular debris. MSC-derived $\mathrm{CM}$ was stored at $-80^{\circ} \mathrm{C}$ until use.

\section{Isolation and identification of EXOs}

After hAD-MSCs reached 90\% confluency, the cells were washed and serum-starved for $6 \mathrm{~h}$ in basal medium (DMEM/F-12; Gibco). Thereafter, the medium was collected and centrifuged at $720 \times \mathrm{g}$ for $30 \mathrm{~min}$ at $4^{\circ} \mathrm{C}$ to remove cellular debris, followed by centrifugation at $100,000 \times \mathrm{g}$ for $100 \mathrm{~min}$ at $4^{\circ} \mathrm{C}$ (Sorvall LYNX-6000, Thermo Fisher Scientific) to sediment the EXOs. The protein content of the concentrated EXOs was measured using the bicinchoninic acid (BCA) protein assay kit (CW0014; CWBiotech, Beijing, China). The morphology of the exosomes was observed using transmission electron microscopy (TEM; JEOL-1200-EX II; JEOL, Tokyo, Japan). Exosomes were identified using specific antibodies targeting CD63 (ab217345, Abcam), CD9 (ab92726, Abcam), CD81 (ab109201, Abcam), and heat shock protein 70 (Hsp70; ab79852, Abcam), which were used for western blotting analysis. All antibodies were diluted to $1: 1,000$.

\section{Animal model and hAD-MSC therapy}

Animal procedures were approved by the Animal Care Unit and Use Committee of Qilu Hospital, China (QLTXB-2019044). Timed pregnant Sprague-Dawley rats (Charles River Co., Beijing, China) spontaneously delivered rat pups. Newborn rats were allocated to five experimental groups: normoxia control, hyperoxia model, hyperoxia with hAD-MSCs, hyperoxia with hAD-MSC-CM, and hyperoxia with hAD-MSC-EXOs ( $\mathrm{n}=12$ per group). Normoxic rat pups were maintained in unmodified air, and hyperoxic rat pups were raised in hyperoxic chambers $\left(80 \% \mathrm{O}_{2}\right)$ from birth until postnatal day $(\mathrm{P}) 14$.

At P7, the pups were anesthetized with ketamine and xylazine via intraperitoneal injection. The trachea was exposed through a small midline incision on the neck. hADMSCs $\left(1 \times 10^{6}\right.$ cells $\left./ 50 \mu \mathrm{L}\right)$, hAD-MSC-CM $(50 \mu \mathrm{L})$, or hAD-MSC-EXOs $(300 \mathrm{ng} / 50 \mu \mathrm{L})$ were delivered by tracheal puncture with a 30-gauge needle. Pups were placed in a warmed plastic chamber under normoxic or hyperoxic conditions for recovery. Once the pups were fully awake, they were returned to their dams. The schematic diagram of the experimental process is shown in Fig. 1A. Survival and body weight of rat pups in each group were checked daily throughout the experiment.

\section{Collection of bronchoalveolar lavage fluid and tissue samples}

After euthanizing the rats pups on P14, the right bronchial tube was ligated. A 20-gauge catheter and $1 \mathrm{~mL}$ cold PBS were used to flushed back and forth three times from trachea to got bronchoalveolar lavage fluid (BALF). The BALF fluid was centrifuged at $720 \times \mathrm{g}$ for $15 \mathrm{~min}$ at $4^{\circ} \mathrm{C}$. The resulting pellet was used to make cell smears and Wright-Giemsa staining was used to count neutrophils. Protein concentration in BALF was then detected by BioRad BCA protein Quantitative Assay Kit (Bio-Rad Labo- 

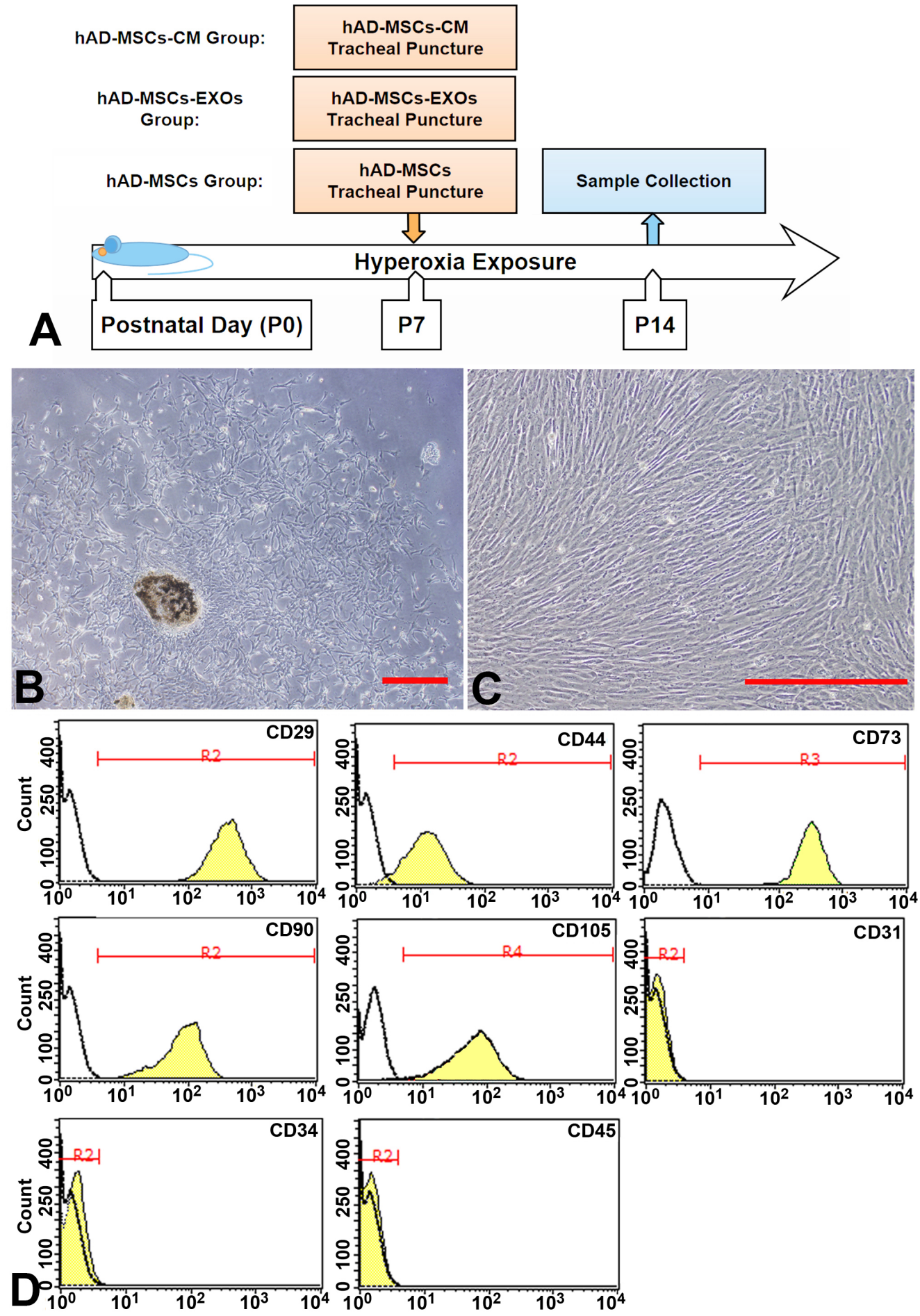

Fig. 1. Characterization of human amniotic mesenchymal stem cells (hAD-MSCs). (A) Overall experimental design process and grouping. (B) Within days of primary culture, small debris of amniotic membrane usually become germinal centers of adherent cells. (C) Adherent cells growing from amniotic tissue mass showed typical fibrous morphology and grew tightly. Bar $=100 \mu \mathrm{m}$. (D) Flow cytometry showed that the cells positively expressed MSC markers (CD29, CD44, CD73, CD90, and CD105), but negatively expressed CD31, CD34, and CD45. 
ratories, Hercules, CA, USA). The right middle lobe was preserved in liquid nitrogen at $-80^{\circ} \mathrm{C}$ for subsequent gene expression analysis. The right upper lobe is used to compare the degree of pulmonary edema. The right lower lobes were used for pathological evaluation.

\section{Cytokine measurement in BALF}

Enzyme-linked immunosorbent assay (ELISA) was used to measure the concentration of tumor necrosis factor- $\alpha$ (TNF- $\alpha$, R\&D Systems, Minneapolis, MN, USA), Interleukin-1 beta (IL-1 $\beta$, Boyun, Shanghai, China), IL-6 (Boyun), and monocyte chemoattractant protein-1 (MCP-1, Boyun) in BALF according to the manufacturer's instructions. The ELISA plate was read at $450 \mathrm{~nm}$ and analyzed according to the standards.

\section{Malondialdehyde concentration in BALF}

Malondialdehyde (MDA) levels in the BALF, the indicator of lipid peroxidation, were detected using a thiobarbituric acid (TBA) photometric Kit (A003-1, Jchio, Nanjing, China) according to the manufacturer's procedures. The absorbance of the organic layer was measured via spectrophotometry at $532 \mathrm{~nm}$ (Pharmacia Biotech, Fleming Island, FL, USA). MDA levels were expressed in $\mathrm{nmol} /$ $\mathrm{mL}$.

\section{Lung histopathology}

For histological analysis, formalin fixed and paraffin-embedded lung tissue was cut into $5-\mu \mathrm{m}$ sections and stained with hematoxylin and eosin. The injury status of each lung were blindly scored by a pathologist in terms of the following four categories: alveolar congestion, hemorrhage, neutrophil infiltration into the airspace or vessel wall, and thickness of alveolar wall/hyaline membrane formation. Each sample was graded on a 0- to 4-point scale: $0=$ no injury; $1=$ injury in up to $25 \%$ of the field; $2=$ injury in up to $50 \%$ of the field; $3=$ injury in up to $75 \%$ of the field; and 4=diffuse injury (13). To perform standardized analysis through lung morphometry, the mean linear intercept (MLI), an indicator of mean alveolar diameter, was assessed in 10 nonoverlapping fields (14).

\section{Lung weight/body weight ratio analysis}

The lung tissue was weighed, and then the wet lung weight was divided by body weight to get the lung weight/ body weight ratio.

\section{Superoxide dismutase activity assay}

SOD activity was analysed by spectrophotometry based on nitroblue tetrazolium (NBT) method (S0109, Beyotime,
Jiangsu, China) according to the manufacturer's procedures. The amount of formazan formed was calculated in absorbance measurements at $560 \mathrm{~nm}$ (Pharmacia Biotech) and was expressed in $\mathrm{U} / \mathrm{mL}$.

\section{Microarray-based gene expression analysis}

TRIzol (Ambion, Life Technologies, Carlsbad, CA, USA) were used to extract total RNA from lung tissue according to the manufacturer's procedures. RNA labeling and hybridization were performed according to the Agilent OneColor Microarray-Based Gene Ex pression Analysis protocol (Agilent Technologies, Santa Clara, CA, USA). Acquired array images were analysed using Agilent Feature Extraction software (version 11.0.1.1). Quantile normalization and subsequent data processing were performed using the GeneSpring GX v12.1 software package (Agilent Technologies). Differentially expressed genes between the two samples were identified through Fold Change filtering. Through the Kyoto Encyclopedia of Genes and Genomes (KEGG; www.genome.jp/kegg/pathway.html) pathway enrichment analysis, significantly enriched pathways were identified in differentially expressed genes (DEGs) with a fold change $\geq$ two.

\section{Quantitative PCR validation of microarray expression data}

Total RNA was extracted from each sample using TRIzol (Invitrogen, Carlsbad, CA, USA). Reverse-transcriptase quantitative PCR (qRT-PCR) was performed to analyze the expression levels of ten genes selected from the above microarray results (the primers used are listed in Table 1). Total RNA was reverse-transcribed to cDNA using the Omniscript cDNA Synthesis Kit (Qiagen, Hamburg, Germany) according to the manufacturer's instructions. qRT-PCR was conducted using an PCR system (Analytik Jena AG, qTOWER3G, Germany) and SYBR green I dye (Toyobo, Osaka, Japan). Glyceraldehyde-3phosphate dehydrogenase (GAPDH) was used as an internal reference control. The expression of each gene was determined using the $2^{-\triangle \Delta C T}$ method. The qPCR conditions were as follows: 40 cycles of $95^{\circ} \mathrm{C}$ for $4 \mathrm{~min}, 94^{\circ} \mathrm{C}$ for $15 \mathrm{~s}$, and $60^{\circ} \mathrm{C}$ for $1 \mathrm{~min}$. Data are reported as the mean \pm standard deviation (SD) of at least three independent experiments. mRNA expression is presented as fold difference with respect to normoxia groups.

\section{Western blot analysis}

Western blots were carried out to analyze the expression of acylaminoacyl-peptide hydrolase (APEH). After electrophoresis and transfer, the membranes were incubated with 
Table 1. Primers used in $q R T-P C R$

\begin{tabular}{lllc}
\hline & \multicolumn{1}{c}{ Primer sequence } & $\begin{array}{c}\text { Product } \\
(\mathrm{bp})\end{array}$ \\
\hline \multirow{2}{*}{ Shank1 } & $\mathrm{F}$ & 5-AGAAATCTATCGGGGCTGCG & 120 \\
& $\mathrm{R}$ & 5-GTGATGTAGTGGGTGGTGGG & \\
Apeh & $\mathrm{F}$ & 5-CACCAATCGCAGATCAGCTC & 124 \\
& $\mathrm{R}$ & 5-GTAGACGATGCGACACTGGT & \\
Slc26a1 & $\mathrm{F}$ & 5-TGTCCCAGATTAGCCAAAGAG & 132 \\
& $\mathrm{R}$ & 5-CCTTCAGTGTTCCAGCAAGC & \\
Ptp4a3 & $\mathrm{F}$ & 5-GCTACCGACACATGCGTTC & 169 \\
& $\mathrm{R}$ & 5-GGCCAGTCCACAACAGTGAT & \\
Rnf19b & $\mathrm{F}$ & 5-CAGCTCCTACAACCCACAGG & 102 \\
& $\mathrm{R}$ & 5-CAAGGCAGCAGGTAAACCAAC & \\
Lrrc2 & $\mathrm{F}$ & 5-CCCACTAGCACAGGGAAGGT & 173 \\
& $\mathrm{R}$ & 5-CCTTATCTTCTCCAGGGCGCTT & \\
Ppm1b & $\mathrm{F}$ & 5-CAAAGACAATGATGGGGGCG & 144 \\
& $\mathrm{R}$ & 5-GGGAATTCACAAGAATAGTCCCC & \\
Fam96a & $\mathrm{F}$ & 5-CGACAGAAGAAGACATCAACAAGC & 125 \\
& $\mathrm{R}$ & 5-CTTAGGAAGGCGTCAGTCCG & \\
Lpo & $\mathrm{F}$ & 5-CAAAATCCTTCCCCCTGGGC & 135 \\
& $\mathrm{R}$ & 5-CAGAAGCACTTCATCACTGCC & \\
Sftpc & $\mathrm{F}$ & 5-GCCCACCGGATTACTCGAC & 111 \\
& $\mathrm{R}$ & 5-CCACGACGACAAGGACTACC & \\
GAPDH & $\mathrm{F}$ & 5-AGTGCCAGCCTCGTCTCATA & 133 \\
& $\mathrm{R}$ & 5-ATGAAGGGGTCGTTGATGGC & \\
\hline & & &
\end{tabular}

the primary antibodies anti-APEH (ab236608, dilution 1 : 2000, Abcam) and anti-actin (ab8227, dilution 1:1000, Abcam), followed by incubation with HRP-conjugated secondary detected by enhanced chemiluminescence (ECL; Beyotime) and quantified using C-Digit (Model: 3600, Image Studio Digits Ver 4.0; Licor, Lincoln, NE, USA).

\section{Statistical analysis}

Data were analyzed using SPSS software version 17.0 (SPSS Inc., Chicago, IL, USA). Quantitative data are described as the mean \pm SD. Data were compared by analysis of variance (ANOVA) or Student's t-test. A value of $p<$ 0.05 was considered statistically significant.

\section{Results}

\section{Characterization of hAD-MSCs and their differentiation capacity}

Initially, amniotic membranes were digested using tryp$\sin$ for $2 \mathrm{~h}$; the remaining tissue was digested by collagenase II. The digested fragments quickly grew into fibroblasts attached to the wall of cell culture flask (Fig. 1B). These adherent cells showed a typical fibrous morphology and grew rapidly, with an average doubling time of 36.4 $\mathrm{h}$ at passage 5 (Fig. 1C). Flow cytometry showed that these cells positive express MSCs markers (CD29, CD44, CD73, CD90, and CD105); and negative express endothelial cell markers (CD31) and hematopoietic markers (CD34 and CD45) (Fig. 1D).

In adipogenic induction group, almost all cells become hypertrophic after 2 weeks. A large number of lipid droplets can be dyed red by oil red $\mathrm{O}$ in the cytoplasm (Fig. 2A). Immunohistochemical staining of type II collagen, marker for chondrocytes, also showed positive results after 21 days of chondrogenic induction (Fig. 2B). After 2 weeks of osteogenic induction, cell aggregation increases and can be stained positive by Alizarin red, which means the formation of mineralized matrix (Fig. 2C), and most MSClike cells were alkaline phosphatase-positive by the end of 14 d (Fig. 2D).

\section{Characterization of hAD-MSC-EXOs}

Serum starvation was used to promote the secretion of exosomes, and exosomes were then precipitated by highspeed centrifugation. The protein concentration was measured to quantify exosomes; an average of $150 \mathrm{ng}$ exosomes per $100 \mathrm{~mL}$ medium was obtained. TEM demonstrated that the hAD-MSC-EXOs had diameters ranging from 30 150 $\mathrm{nm}$ (Fig. 2E). Additionally, we confirmed the expression of the extracellular vesicle (EXOs) markers CD9, CD63, CD81, and Hsp-70 by western blotting (Fig. 2F).

\section{hAD-MSCs more effectively alleviated the inflammatory response in NHLI rats}

Exposure to oxygen (HC) significantly reduced the survival rate to $41.6 \%(\mathrm{p}<0.05$ vs. Normoxia group) at the end of experiment (P14) compared to the $100 \%$ survival rate of Normoxia group. After cell infusion on day P7, the survival rate of the hAD-MSCs group was significantly improved ( $<<0.05$ vs. Hyperoxia group), and no further death occurred. However, survival rates of hAD-MSCEXOs group and hAD-MSC-CM group were lower than that of hAD-MSCs group (Fig. 3A). Hyperoxia exposure also significantly reduced the vitality of the experimental animals; they showed signs of depression, and displayed reduced activity and dietary intake. Additionally, their fur became dull and they showed reduced body weight. Neither cell therapy nor cell-derivative therapy could significantly increase the weight gain of neonatal rats in the experimental group (Fig. 3B). However, the direct transfusion of cells and the transfusion of cell derivatives all successfully reduced the ratio of lung weight/body weight (Fig. 3C) and reduced pulmonary edema, which was further confirmed in tissue sections (Fig. 4A $\sim$ E). We used a five-level quantitative scoring system and MLI value to 


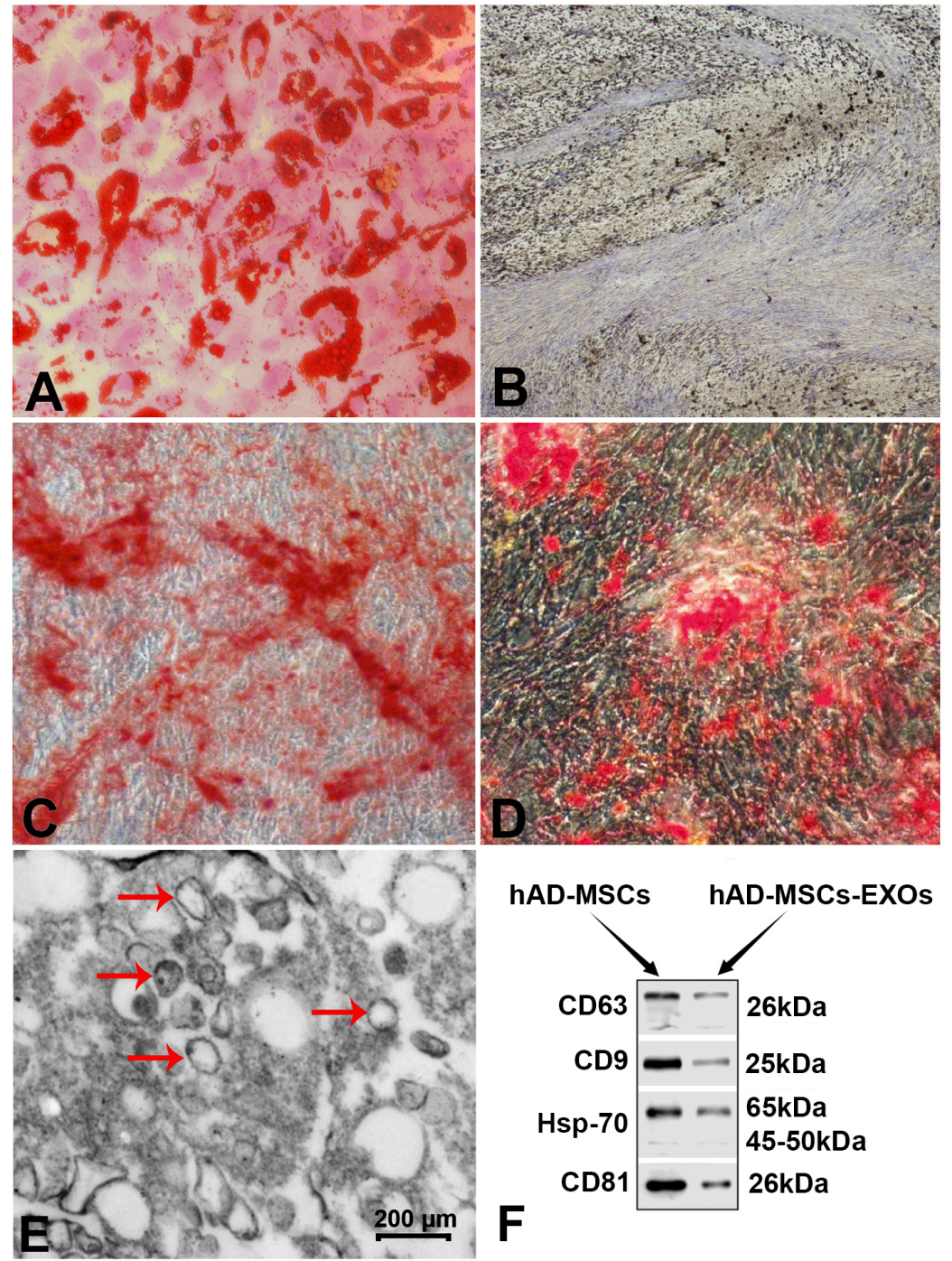

Fig. 2. Differentiation capacity of hAD-MSCs and characterization of hAD-MSC-derived exosomes (EXOs). (A) After adipogenic induction, almost all cells became broad and contained fat droplets dyed by oil red O. (B) After 21 days chondrogenic induction, hAD-MSCs expressed high concentrations of type II collagen, with a brown signal. (C) Under osteogenic conditions, MSCs aggregated, and were stained with Alizarin red, and (D) most cells were found to be alkaline phosphatase-positive, with a red signal. (E) The average diameter of the exosomes was $110 \mathrm{~nm}$. (F) Western blotting indicated that hADMSC-EXOs expressed exosomal markers such as CD63, CD9, Hsp70 and CD81. Magnification: $100 \times$. evaluate the therapeutic effect of hAD-MSCs on NHLI. Hyperoxia resulted in the inflammatory cell infiltration, alveolar septum thickened and the structural destruction of the lung parenchyma. As shown in Fig. $4 \mathrm{~F}$ and $4 \mathrm{G}$, the hyperoxia group exhibited significantly higher lung injury scores and MLI values than the normoxia group. hADMSCs, hAD-MSC-EXOs, and hAD-MSC-CM significantly alleviated pulmonary edema, especially in the hAD-MSCs group ( $\mathrm{p}<0.05$ vs. Hyperoxia group).

We next detected changes of four cytokines (TNF- $\alpha$, IL-1 $\beta$, IL-6, and MCP-1) in BALF, and found that hyperoxia exposure led to a significant increase in these four inflammatory mediator; their expression showed the greatest decrease after the infusion of hAD-MSCs. After the infusion of hAD-MSC-EXOs or hAD-MSC-CM, the expression of inflammatory cytokines also showed a significant decrease, but this effect was not as robust as that of the di- rect tracheal infusion of hAD-MSCs (Fig. 5A D). The same trend was reflected in terms of the number of neutrophils, MDA concentration, and total proteins in BALF (Fig. $5 \mathrm{E} \sim \mathrm{G}$ ). SOD activity in BALF was increased significantly after treatment with hAD-MSCs (Fig. 5H).

\section{Microarray-based gene expression analysis}

Signaling pathways: We compared differentially expressed genes among the different groups using the obtained lung samples. Compared to the normoxia group, the top three up-regulated signaling pathways in the hyperoxia group were calcium signaling, non-homologous end-joining, and neuroactive ligand-receptor interaction, while the top three down-regulated signaling pathways in the hyperoxia group were endocytosis, focal adhesion, and neurotrophin signaling (Fig. 6A). When treated with hAD-MSCs, the top three up-regulated pathways were 

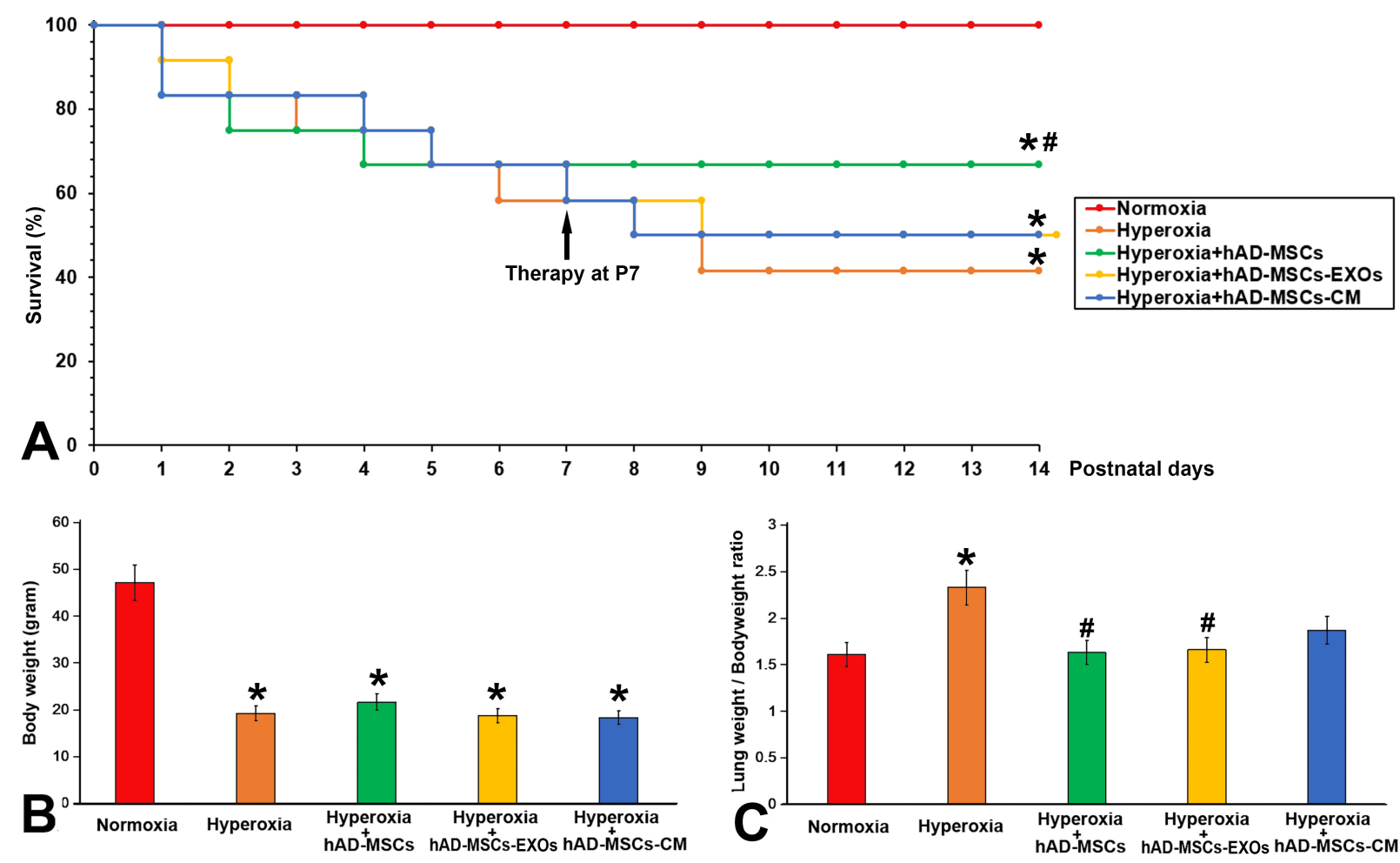

Fig. 3. hAD-MSCs effectively improved survival and body weight. (A) Survival curve. (B) Hyperoxia exposure significantly reduced the body weight of neonatal rats. Treatment with hAD-MSCs and their derivatives did not significantly increase the body weight of neonatal rats. (C) Hyperoxia exposure significantly increased the lung weight/body weight ratio. Both the direct transfusion of cells and the transfusion of cell secretions reversed this increase. At $\mathrm{P} 14:{ }^{*} \mathrm{p}<0.05$ vs. Normoxia group, ${ }^{\#} \mathrm{p}<0.05$ vs. Hyperoxia group.

morphine addiction, calcium signaling, and neuroactive ligand-receptor interaction compared to those in the hyperoxia group. The top three down-regulated signaling pathways in the hAD-MSCs group compared to those in the hyperoxia group were Huntington's disease, non-alcoholic fatty liver disease, and Parkinson's disease (Fig. 6B).

Differentially expressed genes: The expression of four genes was significantly decreased in lungs after hyperoxia injury, but increased significantly after hAD-MSCs treatment: SH3 and multiple ankyrin repeat domains 1 (Shank1), APEH, solute carrier family 26 member 1 (Slc26al), and protein tyrosine phosphatase 4A3 (Ptp4a3). In addition, the expression of six genes was highly upregulated after hyperoxia injury, but significantly decreased after hAD-MSCs treatment: ring finger protein 19B (Rnf19b), leucine rich repeat containing 2 (Lrrc2), protein phosphatase, $\mathrm{Mg} 2+/ \mathrm{Mn} 2+$ dependent $1 \mathrm{~B}(\mathrm{Ppmlb})$, family with sequence similarity 96 member A (Fam96a), lactoperoxidase (Lpo), and surfactant protein C (Sftpc). These genes all showed a change in expression of more than threefold.

\section{Changes in APEH expression were closely related to lung injury and hAD-MSC treatment}

RT-qPCR analysis was performed to confirm the expression profiles obtained by gene chip analysis. As shown in Fig. 6, the changes in the expression levels of APEH were the most significant $(p<0.01$, Fig. $7 \mathrm{~A})$, and the observed changes were consistent with the results of gene chip analysis. The nine other tested genes were eliminated because either their changes were not significant, or their trends were not consistent with the results of gene expression profiling microarrays. Thus, we selected APEH to further verify changes in its expression at the protein level using western blotting. Through gray value quantification, the data showed that APEH expression decreased significantly after hyperoxia injury $(p<0.05)$, but increased significantly after hAD-MSC treatment $(\mathrm{p}<0.01$, Fig. 7B).

\section{Discussion}

In this study, we cultured and isolated hAD-MSCs, and then compared the therapeutic effects of hAD-MSCs, 

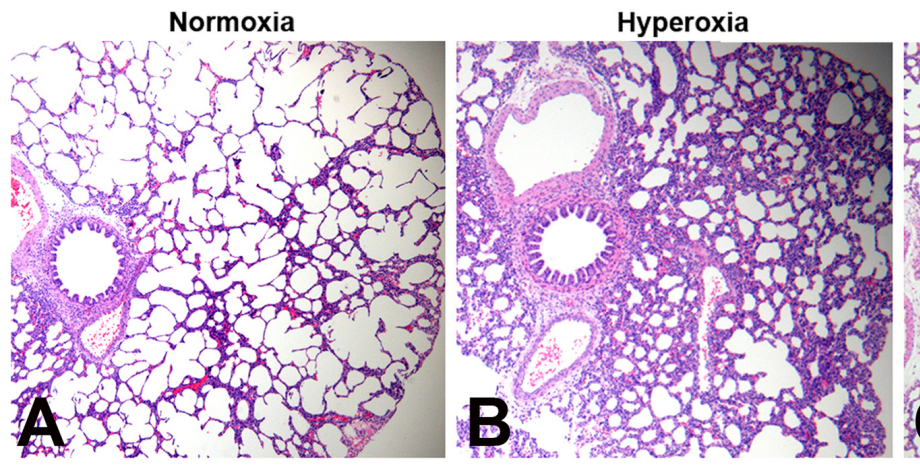

Hyperoxia + hAD-MSCs
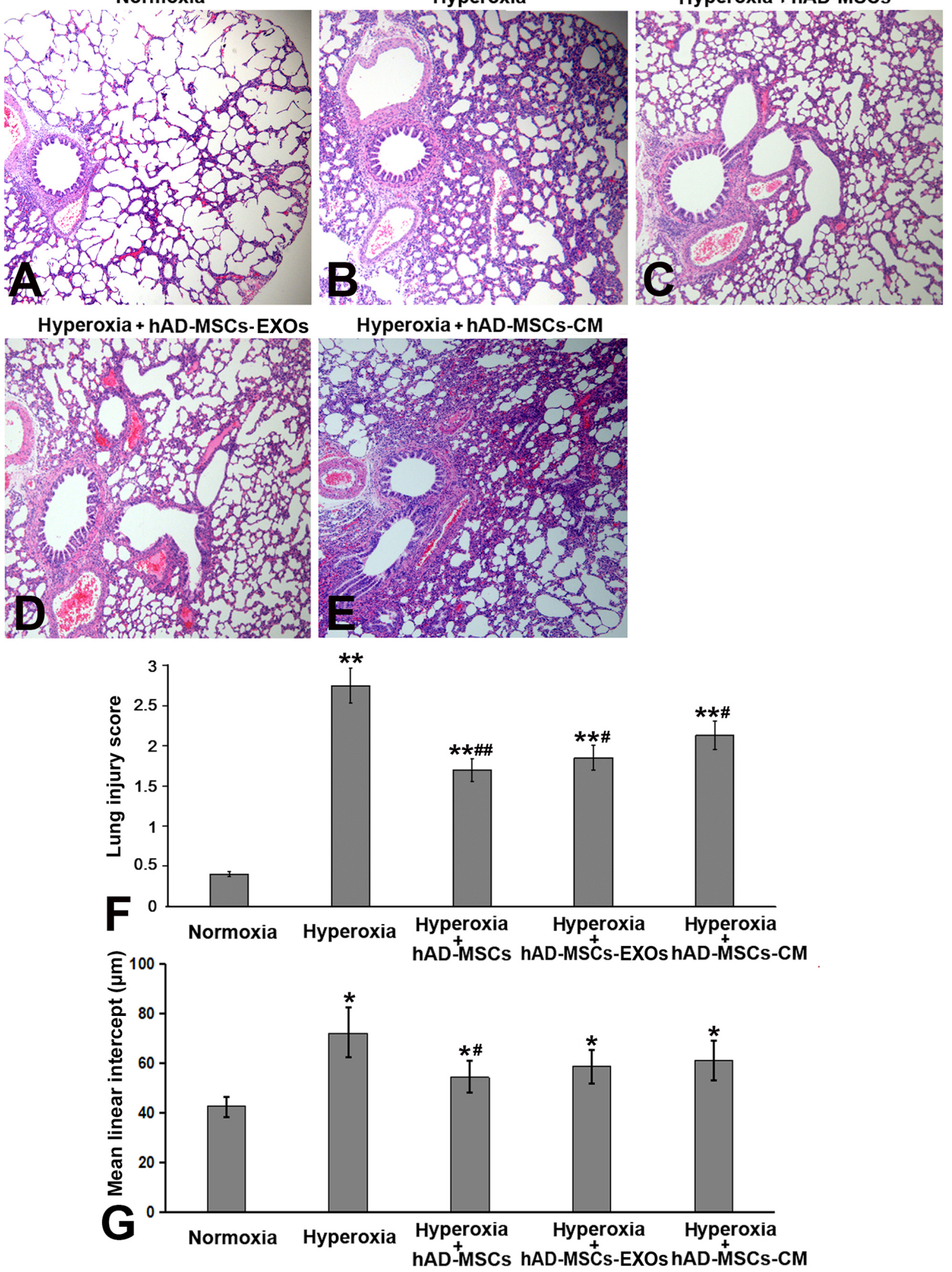

Fig. 4. Histological analysis of neonatal hyperoxic lung injury (NHLI) lungs. (A $\sim$ E) Compared to normoxia exposure (A), hyperoxia exposure (B) caused capillary expansion and alveolar hyperemia, as well as infiltration of neutrophils. The direct transfusion of cells (C), and the transfusion of exosomes (EXOs) (D) and conditioned media (CM) (E) reduced pulmonary edema. (F) To evaluate the effect of hAD-MSCs on NHLI, we used a 5-level evaluation system. hAD-MSCs, hAD-MSC-EXOs, and hAD-MSC-CM significantly alleviated pulmonary edema, especially in the hAD-MSC-treated group. (G) Mean linear intercept (MLI) values in the five groups. The lung tissue sections were assessed through lung morphometry. The hyperoxia group exhibited significantly higher MLI values than the normoxia and three therapy groups. hAD-MSCs treatment significantly reduced the hyperoxia-induced increase in lung injury scores and MLI values. Magnification: $100 \times .{ }^{*} p<0.05$ vs. Normoxia group, ${ }^{* *} \mathrm{p}<0.01$ vs. Normoxia group, ${ }^{\#} \mathrm{p}<0.05$ vs. Hyperoxia group, ${ }^{\#} \mathrm{p}<0.01$ vs. Hyperoxia group. 

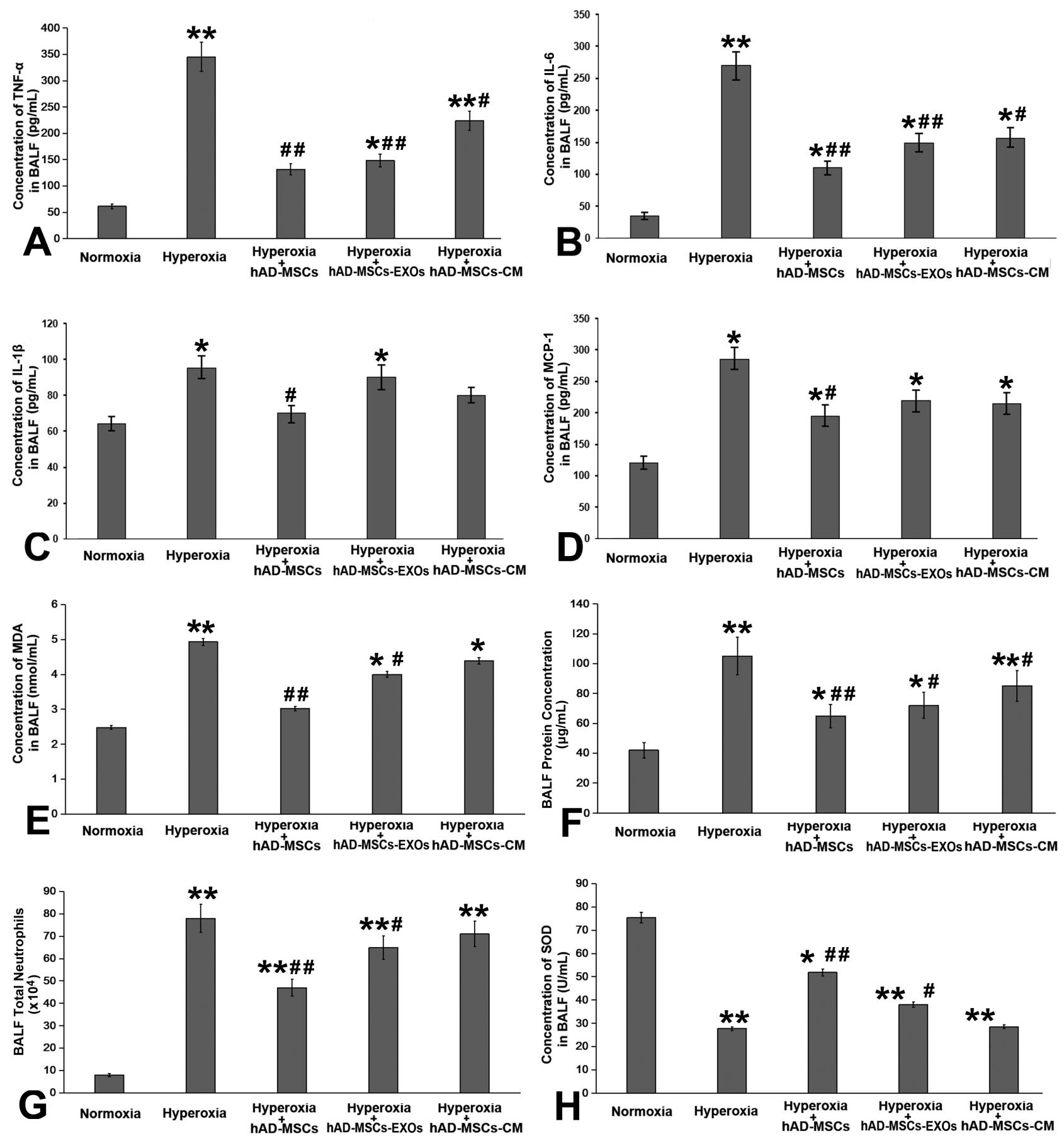

Fig. 5. hAD-MSCs effectively alleviated inflammatory response. Both hAD-MSCs and their derivatives reduced the levels of (A) TNF- $\alpha$, (B) IL-6, (C) IL-1 $\beta$, (D) MCP-1, (E) malondialdehyde (MDA), (F) overall proteins, and (G) neutrophils in bronchoalveolar lavage fluid (BALF); these were all increased after hyperoxia exposure. $(\mathrm{H})$ Hyperoxia exposure significantly decreased the expression of superoxide dismutase (SOD) in BALF. Both hAD-MSCs and hAD-MSC-EXOs significantly increased SOD expression, while hAD-MSC-derived conditioned media (CM) did not. ${ }^{*} \mathrm{p}<0.05$ vs. Normoxia group, ${ }^{* *} \mathrm{p}<0.01$ vs. Normoxia group, ${ }^{\#} \mathrm{p}<0.05$ vs. Hyperoxia group, ${ }^{\#} \mathrm{p}<0.01$ vs. Hyperoxia group.

hAD-MSC-CM, and hAD-MSC-EXOs on NHLI in rats. We systematically investigated the overall changes in body condition, lung index, and inflammatory index of newborn rats. An intratracheal drip of living cells was more effective for treating NHLI than cellular secretions or exosomes in terms of both ameliorating pulmonary edema 


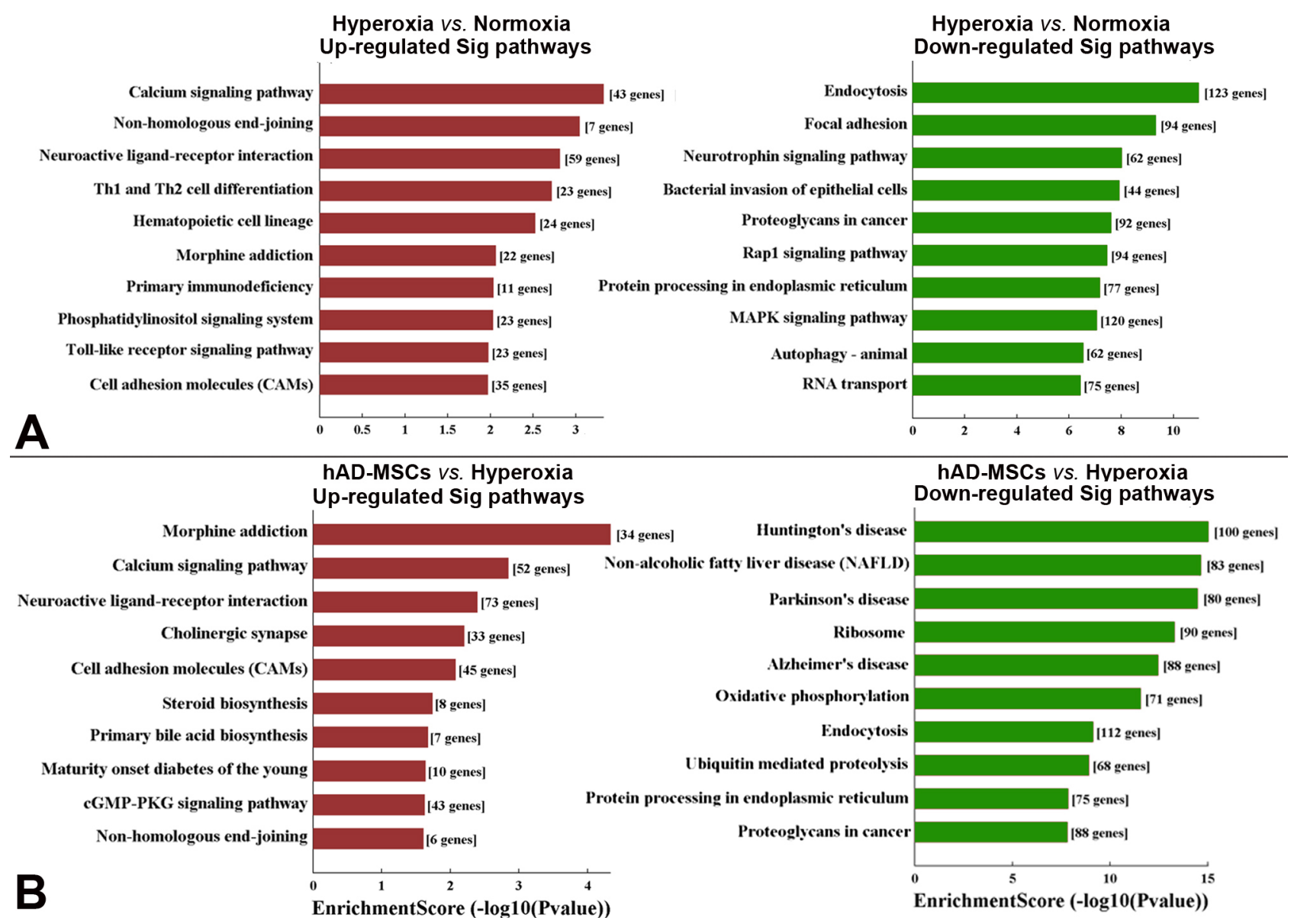

Fig. 6. Microarray gene expression signaling pathway analysis. (A) The most significantly affected signaling pathways in the hyperoxia group compared to those in the normoxia group. (B) The most significantly affected signaling pathways in the hAD-MSCs group compared to those in the hyperoxia group.

and blocking inflammatory cell infiltration. And living cells therapy could better improve the survival rate of animals than secretome. This is primarily because living cells can survive in the lungs for several days and secrete greater concentrations factors and exosomes. Therefore, in subsequent gene analysis, we only evaluated rats in the hAD-MSC group, and underwent a comparative analysis of differential gene expression in lung tissues.

In line with these results, although conditioned medium (CM) contained cytokines including TGF- $\beta$, stromal cell-derived factor 1 (SDF-1), hepatocyte growth factor (HGF), monocyte chemotactic protein 1 (MCP-1), vascular endothelial growth factor-A (VEGF-A), and insulin-like growth factor-1 (IGF-1) (15), the therapeutic effect of CM remained limited (16). For instance, MSCs were previously shown to ameliorate fulminant hepatic failure and chronic liver fibrosis in mice, while MSC-CM could only partially ameliorate hepatic failure (17). In the treatment of acute kidney injury (AKI), although MSC infusion can improve renal function and significantly reduce mortality. However, treatment with $\mathrm{CM}$ showed a non-significant improvement (18). Although cytokines and nucleic acids play a major role in MSC-CM, they are clearly affected by proteases and nucleases in the microenvironment of the body and can only play a short-term role before their degradation. Previous findings showed that the low concentrations of growth factors in non-activated MSC-CM also hampered its clinical application (19). In contrast, MSCs were shown to survive for several days longer in vivo and play a sustained role. After MSCs were i.v. infused into mice, most of the cells were trapped in lung and disappeared with a half-life of about $24 \mathrm{hr}$ (20). Nonhuman primate studies demonstrated that 7 days after infusion of allogeneic or autologous MSCs, only a minor fraction of the cells (less than 3\%) engraft in different tissues (21); the majority of these cells were found in the kidney, lung, 


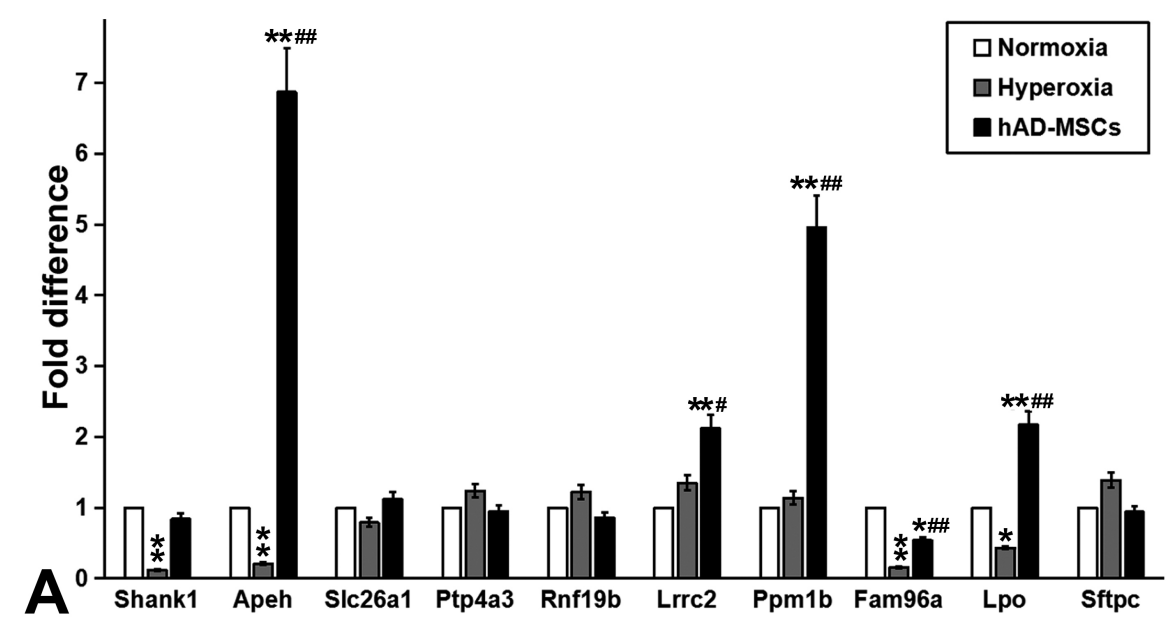

Fig. 7. The expression of APEH is closely related to lung injury and treatment with hAD-MSCs. (A) RTqPCR analysis was performed to confirm the expression profiles obtained from gene chip analysis. (B) The expression of APEH was verified using western blotting. ${ }^{*} \mathrm{p}<0.05$ vs. Normoxia group, $* * p<0.01$ vs. Normoxia group, ${ }^{\#} \mathrm{p}<0.05$ vs. Hyperoxia group, ${ }^{\#} \mathrm{p}<0.01$ vs. B

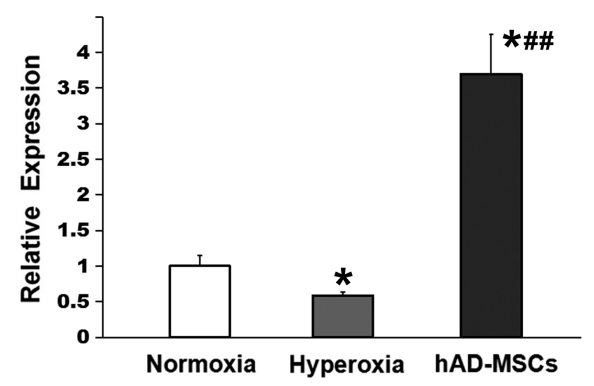
Hyperoxia group.

thymus, and skin (22). Recent findings showed that a very low concentration of MSCs was identified in vivo after 4 weeks (23).

Although the immunoregulatory role of MSCs in vitro and in vivo, they also clearly demonstrate that MSCs cannot completely evade the immune system and are eventually rejected $(24,25)$. Whether MSCs died of immune rejection or inflammation, the benefits of secretion of exosomes and improvement of microenvironment will continue for a period of time. MSCs-derived exosomes provide a protective membrane to protect cytokines and nucleic acids from enzymatic degradation during transport. These small vesicles are widely involved in intercellular communication and can alter the metabolism of target cells or local tissue microenvironment. Recently, MSC-derived exosomes were shown to mediate the therapeutic efficacy of MSCs in various disorders, such as acute kidney injury (26), cardiovascular disease (27), lung injury (28), radiation-induced hematopoietic failure (29), and liver diseases (30). However, high amounts of MSC-CM are required to obtain a small concentration of exosomes. Furthermore, exosomes can only play a one-off role, which is therefore less durable than the continuous production of exosomes by living cells.

In the treatment of BPD, some studies have shown that the intravenous (IT) hMSC administration route is as effective as intratracheal (IV) administrations $(8,9)$. Clinical studies investigating the appropriate dose of IT MSCs for treatment of BPD included doses of $1 \times 10^{7}$ and $2 \times 10^{7}$ cells $/ \mathrm{kg}$. Both doses appeared to be safe without increased short term or long-term adverse events $(31,32)$. Multiple studies have investigated the efficacy of IT MSCs delivery in rat BPD model, and these have typically included doses of $\sim 10^{5}$ cells per rat $(33,34)$. But we found in the pre experiment that a relatively high MSCs IT dose $\left(1 \times 10^{6}\right.$ per rat) resulted in greater animal survival, which showed maximal efficacy as well as favorable safety with this dose.

Many kinds of proinflammatory cytokines are activated during oxidative stress, such as IL-1 $\beta$, IL-6, MCP-1 and TNF- $\alpha(3,35,36)$. High expression of these factors promotes chronic inflammation, leading to the development of BPD. Experiments in neonatal rats have shown that the inhibition of inflammatory factors is beneficial for treating alveolar and lung injury by reducing lung inflammation and oxidative stress. For example, the inhibition of TNF- $\alpha$ can decrease the levels of MDA, which is helpful for lung development and pulmonary vascularization (37). IL-1 $\beta$, IL-6, and MCP-1 are also identified as the biomarkers in monitoring $\operatorname{ALI}(35,36,38)$. In this study, we found that transfusion with hAD-MSCs successfully in- 
hibited the expression of these proinflammatory cytokines in lung tissue. These reduction effects of human MSCs on proinflammatory cytokines are consistent with relevant studies $(39,40)$. These results suggested that the therapeutic effects of MSCs on developing lungs are partially mediated through the inhibition of proinflammatory cytokine production.

These inflammatory microenvironment also affects MSCs. The short-term, low-level exposure with TLR4 agonists polarizes hMSCs toward a pro-inflammatory MSC1 phenotype important for early injury responses $(41,42)$. High level of proinflammatory cytokine may promote anti-inflammatory MSC2, and induce decreased inflammation (43). In addition, hyperoxia augmented proinflammatory M1 macrophage phenotype and inhibited M2 polarization in macrophages (44). However, various tissue-derived MSCs, human adipose tissue-derived MSCs (45), BM-MSCs (46), and amniotic MSCs (47) could induce immunomodulatory M2-like macrophages. These findings revealed that MSCs may suppress inflammatory response and alleviate injuries in BPD mice via M1/M2 macrophages switch (48). Although MSCs administration can increase the pool of M2 macrophage and Tregs, some long term follow up studies ( $>6$ months after intervention) suggest that the beneficial effects of the MSC-therapy wear off with time and may necessitate repeat treatment (49).

Although the mechanism of MSCs in the therapy of NHLI has been explored by many researchers, few studies have focused on significantly differentially expressed genes in lung cells after MSC treatment. Through gene chip hybridization, PCR, and western blotting, we showed that APEH expression was significantly decreased after hyperoxia injury, and increased significantly after hAD-MSC treatment. APEH catalyzes the removal of N-acylated amino acids from acetylated peptides, and has been postulated to play a key role in protein degradation. This proteasome modulates protein homeostasis and controls the turnover of regulatory proteins involved in critical cellular processes, including cell cycle progression and apoptosis (50).

In the process of NHLI, oxidative stress and oxidative damage lead to major lung injury (51). Neutrophils in lung tissue are the main source of reactive oxygen species (ROS). Malondialdehyde (MDA) is the main product of lipid peroxidation. In the assessment of body injury, MDA is mostly used to assess the degree of oxidative damage (52). Our results showed that the intrahracheal transplantation of hAD-MSCs significantly reduced MDA content in NHLI lung tissue, indicating that the redox environment was improved. Recent studies have shown that pre- mature exposure to hyperoxia and the role of ROS are the main risk factors for BPD (53). ROS are highly active oxidants that directly damage cellular structures as well as individual proteins, lipids, and nucleic acids $(54,55)$. ROS can initiate the oxidation and nitrosylation of proteins, resulting in effects such as carbonylation, nitration, and nitrotyrosine formation, and ultimately leading to major cellular dysfunction (56). Cells have developed a whole defense system against ROS, including SOD, catalase and glutathione peroxidase (57). In addition to these enzymes, $\mathrm{APEH}$ is another ubiquitous cytosolic protease, which plays an important role in the detoxification of oxidized proteins.

In mammalian cells, APEH has been found to pay an important role in the clearance of oxidatively damaged proteins, as well as in the degradation of $\beta$-amyloid peptides in Alzheimer's disease (58). Zeng et al. (59) also identified APEH as an integral part of the cellular response to DNA damage. APEH is helpful to repair single-strand DNA breaks after cell injury, and to increase the survival rate of cells exposed to ROS. The infusion of hAD-MSCs into neonatal rats with hyperoxia injury significantly reduced ROS production and MDA levels in this study. This suggests that hAD-MSC could significantly inhibit the production of ROS and reduce the oxidative damage in lung tissue. This effect was shown to be potentially closely related to increased $\mathrm{APEH}$ production.

In summary, the intratracheal application of hAD-MSC ameliorated the symptoms of NHLI in neonatal rats, with APEH playing a major role in this process. Understanding the relationship between APEH expression and lung injury may provide a theoretical basis for the clinical diagnosis and treatment of neonatal lung diseases. For example, measuring changes in $\mathrm{APEH}$ expression after pregnancy may help to quantify the degree of lung injury. Interventions targeting $\mathrm{APEH}$ can potentially improve the long-term quality of life of premature infants with lung injuries.

\section{Acknowledgments}

Projects of Medical and Health Technology Development Program in Shandong Province (2018WS070).

\section{Potential Conflict of Interest}

The authors have no conflicting financial interest.

\section{References}

1. Filippone M, Nardo D, Bonadies L, Salvadori S, Baraldi E. Update on postnatal corticosteroids to prevent or treat bronchopulmonary dysplasia. Am J Perinatol 2019; 
36(Suppl 2):S58-S62

2. Doyle LW, Halliday HL, Ehrenkranz RA, Davis PG, Sinclair JC. Impact of postnatal systemic corticosteroids on mortality and cerebral palsy in preterm infants: effect modification by risk for chronic lung disease. Pediatrics 2005; 115:655-661

3. Yeh TF, Chen CM, Wu SY, Husan Z, Li TC, Hsieh WS, Tsai CH, Lin HC. Intratracheal administration of budesonide/surfactant to prevent bronchopulmonary dysplasia. Am J Respir Crit Care Med 2016;193:86-95

4. Kinsella JP, Greenough A, Abman SH. Bronchopulmonary dysplasia. Lancet 2006;367:1421-1431

5. Kua KP, Lee SW. Systematic review and meta-analysis of clinical outcomes of early caffeine therapy in preterm neonates. Br J Clin Pharmacol 2017;83:180-191

6. Li J, Li D, Liu X, Tang S, Wei F. Human umbilical cord mesenchymal stem cells reduce systemic inflammation and attenuate LPS-induced acute lung injury in rats. J Inflamm (Lond) 2012;9:33

7. Möbius MA, Thébaud B. Stem cells and their mediators-next generation therapy for bronchopulmonary dysplasia. Front Med (Lausanne) 2015;2:50

8. Chang YS, Ahn SY, Yoo HS, Sung SI, Choi SJ, Oh WI, Park WS. Mesenchymal stem cells for bronchopulmonary dysplasia: phase 1 dose-escalation clinical trial. J Pediatr 2014;164:966-972.e6

9. Ahn SY, Chang YS, Kim JH, Sung SI, Park WS. Two-year follow-up outcomes of premature infants enrolled in the phase I trial of mesenchymal stem cells transplantation for bronchopulmonary dysplasia. J Pediatr 2017;185:49-54.e2

10. Díaz-Prado S, Muiños-López E, Hermida-Gómez T, Rendal-Vázquez ME, Fuentes-Boquete I, de Toro FJ, Blanco FJ. Isolation and characterization of mesenchymal stem cells from human amniotic membrane. Tissue Eng Part C Methods 2011;17:49-59

11. Soncini M, Vertua E, Gibelli L, Zorzi F, Denegri M, Albertini A, Wengler GS, Parolini O. Isolation and characterization of mesenchymal cells from human fetal membranes. J Tissue Eng Regen Med 2007;1:296-305

12. Lee OK, Kuo TK, Chen WM, Lee KD, Hsieh SL, Chen $\mathrm{TH}$. Isolation of multipotent mesenchymal stem cells from umbilical cord blood. Blood 2004;103:1669-1675

13. Gupta N, Su X, Popov B, Lee JW, Serikov V, Matthay MA. Intrapulmonary delivery of bone marrow-derived mesenchymal stem cells improves survival and attenuates endotoxin-induced acute lung injury in mice. J Immunol 2007; 179:1855-1863

14. Chou HC, Li YT, Chen CM. Human mesenchymal stem cells attenuate experimental bronchopulmonary dysplasia induced by perinatal inflammation and hyperoxia. Am J Transl Res 2016;8:342-353

15. Shen C, Lie P, Miao T, Yu M, Lu Q, Feng T, Li J, Zu $\mathrm{T}$, Liu X, Li H. Conditioned medium from umbilical cord mesenchymal stem cells induces migration and angiogenesis. Mol Med Rep 2015;12:20-30

16. Devaney J, Horie S, Masterson C, Elliman S, Barry F,
O’Brien T, Curley GF, O’Toole D, Laffey JG. Human mesenchymal stromal cells decrease the severity of acute lung injury induced by E. coli in the rat. Thorax 2015;70:625-635

17. Huang B, Cheng X, Wang H, Huang W, la Ga Hu Z, Wang D, Zhang K, Zhang H, Xue Z, Da Y, Zhang N, Hu Y, Yao Z, Qiao L, Gao F, Zhang R. Mesenchymal stem cells and their secreted molecules predominantly ameliorate fulminant hepatic failure and chronic liver fibrosis in mice respectively. J Transl Med 2016;14:45

18. Xing L, Cui R, Peng L, Ma J, Chen X, Xie RJ, Li B. Mesenchymal stem cells, not conditioned medium, contribute to kidney repair after ischemia-reperfusion injury. Stem Cell Res Ther 2014;5:101

19. Chen H, Min XH, Wang QY, Leung FW, Shi L, Zhou Y, Yu T, Wang CM, An G, Sha WH, Chen QK. Pre-activation of mesenchymal stem cells with TNF- $\alpha$, IL-1 $\beta$ and nitric oxide enhances its paracrine effects on radiation-induced intestinal injury. Sci Rep 2015;5:8718

20. Lee RH, Pulin AA, Seo MJ, Kota DJ, Ylostalo J, Larson BL, Semprun-Prieto L, Delafontaine P, Prockop DJ. Intravenous hMSCs improve myocardial infarction in mice because cells embolized in lung are activated to secrete the anti-inflammatory protein TSG-6. Cell Stem Cell 2009;5:5463

21. Devine SM, Cobbs C, Jennings M, Bartholomew A, Hoffman R. Mesenchymal stem cells distribute to a wide range of tissues following systemic infusion into nonhuman primates. Blood 2003;101:2999-3001

22. Gao J, Dennis JE, Muzic RF, Lundberg M, Caplan AI. The dynamic in vivo distribution of bone marrow-derived mesenchymal stem cells after infusion. Cells Tissues Organs 2001;169:12-20

23. Li D, Liu Q, Qi L, Dai X, Liu H, Wang Y. Low levels of TGF- $\beta 1$ enhance human umbilical cord-derived mesenchymal stem cell fibronectin production and extend survival time in a rat model of lipopolysaccharide-induced acute lung injury. Mol Med Rep 2016;14:1681-1692

24. Eliopoulos N, Stagg J, Lejeune L, Pommey S, Galipeau J. Allogeneic marrow stromal cells are immune rejected by MHC class I- and class II-mismatched recipient mice. Blood 2005;106:4057-4065

25. Zangi L, Margalit R, Reich-Zeliger S, Bachar-Lustig E, Beilhack A, Negrin R, Reisner Y. Direct imaging of immune rejection and memory induction by allogeneic mesenchymal stromal cells. Stem Cells 2009;27:2865-2874

26. Lin KC, Yip HK, Shao PL, Wu SC, Chen KH, Chen YT, Yang CC, Sun CK, Kao GS, Chen SY, Chai HT, Chang $\mathrm{CL}$, Chen $\mathrm{CH}$, Lee MS. Combination of adipose-derived mesenchymal stem cells (ADMSC) and ADMSC-derived exosomes for protecting kidney from acute ischemia-reperfusion injury. Int J Cardiol 2016;216:173-185

27. H Huang L, Ma W, Ma Y, Feng D, Chen H, Cai B. Exosomes in mesenchymal stem cells, a new therapeutic strategy for cardiovascular diseases? Int J Biol Sci 2015;11: 238-245

28. Xu S, Liu C, Ji HL. Concise review: therapeutic potential 
of the mesenchymal stem cell derived secretome and extracellular vesicles for radiation-induced lung injury: progress and Hypotheses. Stem Cells Transl Med 2019;8:344-354

29. Schoefinius JS, Brunswig-Spickenheier B, Speiseder T, Krebs S, Just U, Lange C. Mesenchymal stromal cell-derived extracellular vesicles provide long-term survival after total body irradiation without additional hematopoietic stem cell support. Stem Cells 2017;35:2379-2389

30. Lou G, Chen Z, Zheng M, Liu Y. Mesenchymal stem cell-derived exosomes as a new therapeutic strategy for liver diseases. Exp Mol Med 2017;49:e346

31. Wilson JG, Liu KD, Zhuo H, Caballero L, McMillan M, Fang X, Cosgrove K, Vojnik R, Calfee CS, Lee JW, Rogers AJ, Levitt J, Wiener-Kronish J, Bajwa EK, Leavitt A, McKenna D, Thompson BT, Matthay MA. Mesenchymal stem (stromal) cells for treatment of ARDS: a phase 1 clinical trial. Lancet Respir Med 2015;3:24-32

32. Simones AA, Beisang DJ, Panoskaltsis-Mortari A, Roberts $\mathrm{KD}$. Mesenchymal stem cells in the pathogenesis and treatment of bronchopulmonary dysplasia: a clinical review. Pediatr Res 2018;83:308-317

33. Chang YS, Oh W, Choi SJ, Sung DK, Kim SY, Choi EY, Kang S, Jin HJ, Yang YS, Park WS. Human umbilical cord blood-derived mesenchymal stem cells attenuate hyperoxia-induced lung injury in neonatal rats. Cell Transplant 2009;18:869-886

34. Pierro M, Ionescu L, Montemurro T, Vadivel A, Weissmann G, Oudit G, Emery D, Bodiga S, Eaton F, Péault B, Mosca F, Lazzari L, Thébaud B. Short-term, long-term and paracrine effect of human umbilical cord-derived stem cells in lung injury prevention and repair in experimental bronchopulmonary dysplasia. Thorax 2013;68: 475-484

35. Wu Q, Chong L, Shao Y, Chen S, Li C. Lipoxin A4 reduces hyperoxia-induced lung injury in neonatal rats through PINK1 signaling pathway. Int Immunopharmacol 2019;73: 414-423

36. Wagenaar GT, ter Horst SA, van Gastelen MA, Leijser LM, Mauad T, van der Velden PA, de Heer E, Hiemstra PS, Poorthuis BJ, Walther FJ. Gene expression profile and histopathology of experimental bronchopulmonary dysplasia induced by prolonged oxidative stress. Free Radic Biol Med 2004;36:782-801

37. Oncel MY, Yurttutan S, Alyamac Dizdar E, Gokce IK, Gonul II, Topal T, Canpolat FE, Dilmen U. Beneficial effect of etanercept on hyperoxic lung injury model in neonatal rats. J Invest Surg 2016;29:1-5

38. Chen C, Shi L, Li Y, Wang X, Yang S. Disease-specific dynamic biomarkers selected by integrating inflammatory mediators with clinical informatics in ARDS patients with severe pneumonia. Cell Biol Toxicol 2016;32:169-184

39. Zhang H, Fang J, Su H, Yang M, Lai W, Mai Y, Wu Y. Bone marrow mesenchymal stem cells attenuate lung inflammation of hyperoxic newborn rats. Pediatr Transplant 2012;16:589-598

40. Zhang X, Wang H, Shi Y, Peng W, Zhang S, Zhang W,
Xu J, Mei Y, Feng Z. Role of bone marrow-derived mesenchymal stem cells in the prevention of hyperoxia-induced lung injury in newborn mice. Cell Biol Int 2012;36:589-594

41. Waterman RS, Tomchuck SL, Henkle SL, Betancourt AM. A new mesenchymal stem cell (MSC) paradigm: polarization into a pro-inflammatory MSC1 or an Immunosuppressive MSC2 phenotype. PLoS One 2010;5:e10088

42. Romieu-Mourez R, François M, Boivin MN, Bouchentouf M, Spaner DE, Galipeau J. Cytokine modulation of TLR expression and activation in mesenchymal stromal cells leads to a proinflammatory phenotype. J Immunol 2009; 182:7963-7973

43. Li W, Ren G, Huang Y, Su J, Han Y, Li J, Chen X, Cao K, Chen Q, Shou P, Zhang L, Yuan ZR, Roberts AI, Shi S, Le AD, Shi Y. Mesenchymal stem cells: a double-edged sword in regulating immune responses. Cell Death Differ 2012;19:1505-1513

44. Syed MA, Bhandari V. Hyperoxia exacerbates postnatal inflammation-induced lung injury in neonatal BRP-39 null mutant mice promoting the M1 macrophage phenotype. Mediators Inflamm 2013;2013:457189

45. Manferdini C, Paolella F, Gabusi E, Gambari L, Piacentini A, Filardo G, Fleury-Cappellesso S, Barbero A, Murphy M, Lisignoli G. Adipose stromal cells mediated switching of the pro-inflammatory profile of M1-like macrophages is facilitated by PGE2: in vitro evaluation. Osteoarthritis Cartilage 2017;25:1161-1171

46. Chiossone L, Conte R, Spaggiari GM, Serra M, Romei C, Bellora F, Becchetti F, Andaloro A, Moretta L, Bottino C. Mesenchymal stromal cells induce peculiar alternatively activated macrophages capable of dampening both innate and adaptive immune responses. Stem Cells 2016;34:1909-1921

47. Magatti M, Vertua E, De Munari S, Caro M, Caruso M, Silini A, Delgado M, Parolini O. Human amnion favours tissue repair by inducing the M1-to-M2 switch and enhancing M2 macrophage features. J Tissue Eng Regen Med 2017;11:2895-2911

48. Ren W, Hou J, Yang C, Wang H, Wu S, Wu Y, Zhao X, $\mathrm{Lu}$ C. Extracellular vesicles secreted by hypoxia pre-challenged mesenchymal stem cells promote non-small cell lung cancer cell growth and mobility as well as macrophage M2 polarization via miR-21-5p delivery. J Exp Clin Cancer Res 2019;38:62

49. Dave M, Jaiswal P, Cominelli F. Mesenchymal stem/stromal cell therapy for inflammatory bowel disease: an updated review with maintenance of remission. Curr Opin Gastroenterol 2017;33:59-68

50. Chen D, Dou QP. The ubiquitin-proteasome system as a prospective molecular target for cancer treatment and prevention. Curr Protein Pept Sci 2010;11:459-470

51. Iyer SS, Jones DP, Brigham KL, Rojas M. Oxidation of plasma cysteine/cystine redox state in endotoxin-induced lung injury. Am J Respir Cell Mol Biol 2009;40:90-98

52. Tahara $M$, Nakayama $M$, Jin $M B$, Fujita $M$, Suzuki $T$, Taniguchi M, Shimamura T, Furukawa H, Todo S. A radical scavenger, edaravone, protects canine kidneys from is- 
chemia-reperfusion injury after 72 hours of cold preservation and autotransplantation. Transplantation 2005;80:213221

53. Wang J, Dong W. Oxidative stress and bronchopulmonary dysplasia. Gene 2018;678:177-183

54. Cadenas S. ROS and redox signaling in myocardial ischemia-reperfusion injury and cardioprotection. Free Radic Biol Med 2018;117:76-89

55. Sies H. Hydrogen peroxide as a central redox signaling molecule in physiological oxidative stress: oxidative eustress. Redox Biol 2017;11:613-619

56. Tiganis T. Reactive oxygen species and insulin resistance: the good, the bad and the ugly. Trends Pharmacol Sci 2011; 32:82-89

57. Abele D, Puntarulo S. Formation of reactive species and induction of antioxidant defence systems in polar and temperate marine invertebrates and fish. Comp Biochem Physiol A Mol Integr Physiol 2004;138:405-415

58. García-Rojo G, Gámiz F, Ampuero E, Rojas-Espina D, Sandoval R, Rozas C, Morales B, Wyneken U, Pancetti F. In vivo sub-chronic treatment with dichlorvos in young rats promotes synaptic plasticity and learning by a mechanism that involves acylpeptide hydrolase instead of acetylcholinesterase inhibition. Correlation with endogenous $\beta$ -amyloid levels. Front Pharmacol 2017;8:483

59. Zeng Z, Rulten SL, Breslin C, Zlatanou A, Coulthard V, Caldecott KW. Acylpeptide hydrolase is a component of the cellular response to DNA damage. DNA Repair (Amst) 2017;58:52-61 